\title{
Prevalence and nature of communication delays in a South African primary healthcare context
}

\author{
J van der Linde, ${ }^{1}$ MCommunication Pathology; D W Swanepoel, ${ }^{1,2} \mathrm{PhD} ; \mathbf{J}$ Sommerville, ${ }^{3} \mathrm{MSc} ; \mathrm{F}$ Glascoe ${ }^{4} \mathrm{PhD}$; \\ B Vinck, ${ }^{1,5} \mathrm{PhD}$; E M Louw, ${ }^{3} \mathrm{PhD}$ \\ ${ }^{1}$ Department of Speech-Language Pathology and Audiology, Faculty of Humanities, University of Pretoria, South Africa \\ ${ }^{2}$ Ear Sciences Centre, School of Surgery, University of Western Australia, Nedlands, Australia; and Ear Science Institute Australia, Subiaco, \\ Australia \\ ${ }^{3}$ Department of Statistics, Faculty of Natural and Agricultural Sciences, University of Pretoria, South Africa \\ ${ }^{4}$ School of Medicine, Vanderbilt University, Nashville, Tennessee, USA \\ ${ }^{5}$ Department of Speech-Language Pathology and Audiology, Ghent University, Belgium
}

Corresponding author: J van der Linde (jeannie.vanderlinde@up.ac.za)

\begin{abstract}
Background. Communication delays are the most common impairment in early childhood and have a negative effect on long-term academic, psychological and social development. Baseline prevalence of communication delays or disorders enables adequate planning of service delivery and successful implementation of intervention strategies, to reduce disorder prevalence.

Objective. To determine the prevalence and describe the nature of communication delays in infants aged 6 - 12 months in underserved communities in South Africa (SA).

Method. A parent interview and the Rossetti Infant-Toddler Language Scale (RITLS) were used to collect data from the caregivers of 201 infants aged 6 - 12 months by means of convenience sampling at primary healthcare facilities in the Tshwane district, SA.

Results. Thirteen percent $(n=26)$ of infants were diagnosed with communication delay. Associations affecting language delays were established for three risk factors (i.e. housing status, age of mother and number of siblings). The effect of combined risk factors on language development revealed that an infant was at greatest risk (27\% probability) of developing a language delay when: ( $i$ ) mothers were between the ages of 19 and 34 years; (ii) parents owned their own home; and (iii) there were three or more children in the household.

Conclusion. The prevalence of communication delays in the sample population was high, possibly because the majority of infants were exposed to risk factors. The implementation of preventive measures such as awareness campaigns and developmental screening and surveillance should be considered in the SA primary healthcare context.
\end{abstract}

S Afr J Child Health 2016;10(1):87-91. DOI:10.7196/SAJCH.2016.v10i1.1121

Communication delays are the most common impairment in early childhood $^{[1]}$ and have a negative effect on long-term academic, psychological and social development. ${ }^{[2,3]}$ Early identification of, and early intervention for, communication delays in infants minimise the effect of the delay on educational and social outcomes. ${ }^{[2]}$ Reported prevalence of communication delays varies significantly within countries and internationally. ${ }^{[2,4,5]}$ In the UK a communication delay prevalence of $16.3 \%$ in children has been reported. ${ }^{[1]}$ Similar findings (prevalence of $16.5 \%$ and $11.6 \%$ ) were reported in school-going children in Sydney, Australia. ${ }^{[6]}$ In contrast, other studies have reported much lower figures, such as $1.4 \%{ }^{[7]}$ and $8.0 \%{ }^{[8]}$ More specifically, a systematic review reported that $15 \%$ of 2 -year-olds presented with expressive language delays. ${ }^{[9,10]}$ Possible reasons for the variability is the presence of risk factors, difficulty assessing infants and toddlers and the limited availability of well-developed assessment tools. ${ }^{[2,4]}$

Risk factors such as poverty, lack of stable residence, limited prenatal care and inadequate healthcare facilities contribute to communication delays in infants. ${ }^{[11]}$ People living in underserved communities, e.g. in informal settlements in South Africa (SA), experience a double burden of poverty and ill health as the environment they live in influences child development. ${ }^{[1]}$ Residential density, living in crowded homes and poor-quality housing lead to parents being less interactive with their children, which in turn has a negative effect on communication development. ${ }^{[12]}$ Also, a gender bias exists, with males more likely to present with communication delays than females. ${ }^{[1,4]}$

Apart from risks, identification of communication delays in infants is difficult as development occurs over time, resulting in varied prevalence rates. ${ }^{[1,4]}$ Most parents only discover their child's communication delays when he or she fails to meet typical developmental milestones. ${ }^{[2]}$
Ironically, the most important period of communication acquisition and development is between 8 months and 2 years. ${ }^{[2]}$ Studies reporting the prevalence of communication delays in infants younger than 2 years are limited. ${ }^{[2,4]}$ This is problematic as prevalence rates vary across the ages of infants and young children. ${ }^{[1]}$

Establishing the prevalence of communication delays or disorders enables appropriate planning for service delivery and successful implementation of intervention strategies, which may ultimately result in a decline in the prevalence of the disorder. ${ }^{[4]}$ Despite previous efforts $^{[13]}$ to improve early identification of infants with delayed communication development in primary healthcare settings of SA, this practice remains uncommon. ${ }^{[14]}$ Establishing the prevalence of communication delays in infants from underserved communities in SA will, however, advocate for the implementation of early identification and intervention services.

An adequate understanding of the prevalence and nature of communication delays in a specific population improves classification of communication delays. ${ }^{[1]}$ Previous research has focused only on speech and receptive and expressive language delays and has not evaluated all the aspects of communication development such as pragmatics and interaction-attachment. ${ }^{[4]}$ Most large-scale prevalence studies have used a broad classification of communication delays, and as a result the true nature of these delays has been obscured. ${ }^{[1]}$ Understanding the nature of communication delays allows predictions that are of clinical and research significance, i.e. early use of gestures predicts later vocabulary development and early word use predicts later social-emotional development. ${ }^{[15]}$ Since there is a dearth of information on the prevalence and nature of communication delays in infants 12 months and younger, the 
objective of this study was to determine the prevalence and nature of communication delays in infants aged $6-12$ months in underserved communities in SA.

\section{Methods}

A prospective cross-sectional study was employed to determine the prevalence and nature of communication delays in infants from underserved SA communities. Prior to data collection, permission and ethical clearance was obtained from the Tshwane district research committee, Department of Health, and the Faculties of Health Sciences and Humanities, University of Pretoria.

\section{Setting}

Three clinics (Olievenhoutbosch clinic, Salvokop clinic and Daspoort Polyclinic), situated in underserved communities of the Tshwane district, Gauteng Province, SA, were utilised for data collection. Olievenhoutbosch clinic serves a population of 70863 individuals residing in an area of $11.39 \mathrm{~km}^{2}{ }^{[16]}$ Both Salvokop and Daspoort form part of the Pretoria sub-district. The clinic situated in Salvokop area serves a population of 7123 and Daspoort clinic a population of 6355 individuals. $^{[16]}$

\section{Participants}

A total of 201 participants were included in the study by means of convenience sampling. All the parents or caregivers of infants aged between 6 and 12 months, who were proficient in Afrikaans or English, were asked to participate during their visit to the primary healthcare clinic (PHC). Gender distribution of infants was similar (55\% male). The home languages spoken most were Sepedi (33\%), isiZulu (16\%), chiShona (11\%) and Ndebele (10\%). Ninety-four percent of the participants resided in the Olievenhoutbosch area; the remainder were from other areas such as Salvokop (2\%) and Mamelodi (0.5\%). The majority of participants (98.5\%) were black, with $1.5 \%$ from other ethnic groups.

Seven infants (of 201 participants) had been born to teenage mothers. Altogether 62\% of parents or caregivers left the educational system at Grade 10 or less and $71 \%$ reported a household income of less than ZAR3 000 a month. About one-third (32\%) of infants have two or more siblings. In general $17 \%$ of South Africans (20 years or older) are functionally illiterate, $34 \%$ completed some secondary levels of education and $29 \%$ completed Grade $12 .{ }^{[16]}$ Furthermore, $46 \%$ of the SA population is deemed poor. ${ }^{[17,18]}$

\section{Material}

A structured interview schedule was developed to obtain participant background information, i.e. date of birth, duration of pregnancy, and gender.
The Rossetti Infant-Toddler Language Scale (RITLS) is a comprehensive, easy-to-administer and relevant tool to assess the preverbal and verbal communicative abilities and interaction in infants and young children. ${ }^{[19]}$ Although this is a criterion-referenced tool, it has been used and validated in the past. ${ }^{[20-23]}$ The tool assesses the following domains: pragmatics, gesture, play, language comprehension, language expression and interaction-attachment. When an infant has one (or more) unmet milestone(s) in a specific developmental domain (such as language expression) at a specific age interval, the milestones of the previous interval are evaluated until the infant has met all the milestones at that age interval. The infant's developmental level is therefore categorised as the interval at which he/she obtained all the milestones within a domain. An infant's development is classified as delayed when domain-specific developmental levels differed 6 months or more from the chronological age (e.g. when a 12-month-old infant's language expression scored on a 3 - 6-month-old developmental level). ${ }^{[19]}$

As the first items in the gesture subdomain only start at $9-12$ months, an infant can only present with a delay when he/she is 15 months or older. Since participants in the study were all between 6 and 12 months of age and their development of gestures could not be classified as delayed, this subdomain was excluded from the results.

\section{Procedures}

An experienced speech-language pathologist collected all the data. Parental/caregiver informed consent was obtained before data collection commenced. First the parent interview, and then the RITLS, was conducted on each participant. The RITLS was completed by observing and eliciting infant behaviour and also by making use of parental responses.

\section{Data analysis}

A statistical software program, SAS (version 9.3), was used to conduct the data analysis.
Descriptive statistics were used to describe the prevalence and nature of communication delays in a group of infants. To determine the existence of a significant association between risks and the delayed outcome of the receptive and/or expressive language domains of the RITLS, the $\chi^{2}$ and Fisher's exact test statistics were used with a significance level of $p \leq 0.05$ and $p \leq 0.1$.

Risk factors significantly associated with receptive and/or expressive language delays $(p \leq 0.05, p \leq 0.1)$ were included in the second phase of the statistical analysis where a $\log$ linear model analysis was used to model the probabilities of developing language delays, taking into account both single and simultaneous effects of the relevant risks. Since only three factors were significant at 5\% probability, a probability of $10 \%$ was used to add additional factors into the model. Maternal education was included as the fourth factor with a $10 \%$ probability $(p=0.095)$. Since the data on the age of the mother were too limited in the category $\leq 18$ years $(n=7)$, this category had to be excluded in the log linear analysis. Although a maternal age of $19-34$ years is not considered an environmental risk, the effect of age for mothers aged $\geq 35$ had to be explored alongside the low-risk group.

The outcomes of the model were expressed as indices and converted into odds of language delays for a specific combination of categories of risk factors. Based on the odds, the estimated probability to have a language (receptive and/ or expressive) delay for a specific combination of risks was calculated using the following formula: $\operatorname{prob}=$ odds $/(1+$ odds $)$.

\section{Results}

Of the 201 participants, $13.0 \%(n=26)$ were diagnosed with communication delay, i.e. a delay in one or more of the communication domains of the RITLS. The delayed infants were evenly distributed in terms of gender (54\% male). The majority of delayed infants $(58 \%)$ presented with a delay in one communication domain (Fig. 1).

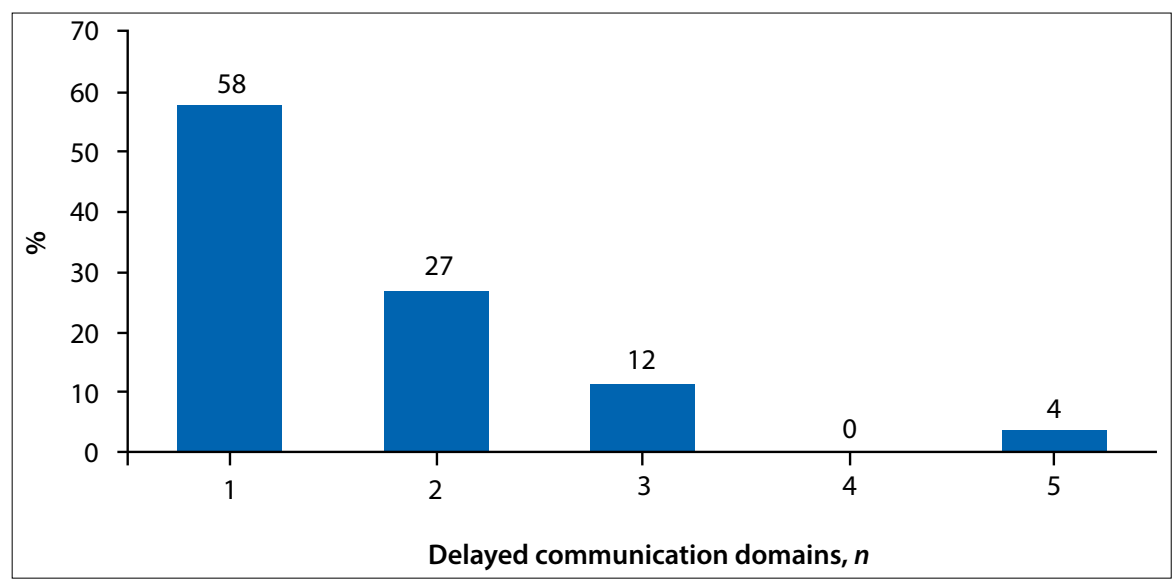

Fig. 1. Distribution of the number of delayed communication domains in participants with delays $(\mathrm{n}=26)$. 
Only $4 \%$ of infants with a positive diagnosis presented with delays in five of the domains. The prevalence rates for the domain-specific outcomes of the RITLS are presented in Table 1. Most participants with a positive diagnosis $(22 / 26 ; 84.6 \%)$ presented with delayed language expression. Nine of the delayed participants $(9 / 26 ; 34.6 \%)$ presented with delayed language comprehension and only two participants $(2 / 26 ; 7.7 \%)$ had a delay in their interaction attachment skills.

Associations between risks and delays in language expression and/or comprehension are presented in Table 2. Three risks were found to be significantly associated with language delays in the study population, namely:

- Infants of mothers with three or more children had significantly higher prevalence of

Table 1. Domain-specific outcomes of the RITLS for all participants $(N=201)$

\begin{tabular}{lll}
\hline Domains & No delay, $\boldsymbol{n}(\%)$ & Delay, $\boldsymbol{n}(\%)$ \\
\hline Pragmatics & $197(98.0)$ & $4(2.0)$ \\
Play & $195(97.0)$ & $6(3.0)$ \\
Interaction-attachment & $199(99.0)$ & $2(1.0)$ \\
Language expression & $179(89.1)$ & $22(10.9)$ \\
Language comprehension & $192(95.5)$ & $9(4.5)$
\end{tabular}

Table 2. Association of language delays with risk factors

\begin{tabular}{|c|c|c|c|}
\hline Risk factors & Delayed (\%) & $\begin{array}{l}\text { Significance } \\
(p \text {-value })\end{array}$ & Test statistic \\
\hline \multicolumn{4}{|l|}{ Level of education $(n=200)$} \\
\hline Grade 10 or less $(n=66)$ & 17 & $0.095^{*}$ & $x^{2}$ \\
\hline $\begin{array}{l}\text { Grade } 11-12 \text {, and/or tertiary education } \\
(n=134)\end{array}$ & 10 & & \\
\hline \multicolumn{4}{|l|}{ Number of children $(n=201)$} \\
\hline$\leq 2(n=135)$ & 9 & $0.0564^{\dagger}$ & $x^{2}$ \\
\hline$\geq 3(n=66)$ & 18 & & \\
\hline \multicolumn{4}{|l|}{ Prematurity $(n=201)$} \\
\hline 0 - 2 months premature $(n=195)$ & 12 & 0.5385 & Fisher's exact \\
\hline$\geq 3$ months premature $(n=6)$ & 17 & & \\
\hline \multicolumn{4}{|l|}{ Employment $(n=201)$} \\
\hline Yes $(n=173)$ & 12 & 0.7524 & Fisher's exact \\
\hline No $(n=28)$ & 14 & & \\
\hline \multicolumn{4}{|l|}{ Housing status $(n=201)$} \\
\hline Home owners $(n=47)$ & 21 & $0.0241^{\dagger}$ & $x^{2}$ \\
\hline $\begin{array}{l}\text { Informal housing or staying with others } \\
(n=154)\end{array}$ & 10 & & \\
\hline \multicolumn{4}{|l|}{ Gender ( $n=201)$} \\
\hline Male $(n=111)$ & 11 & 0.5834 & $x^{2}$ \\
\hline Female $(n=90)$ & 13 & & \\
\hline \multicolumn{4}{|l|}{ Average household income $(n=199)$} \\
\hline$<$ ZAR1 $500(n=80)$ & 9 & 0.3097 & $\chi^{2}$ \\
\hline$\geq$ ZAR1 $500(n=119)$ & 13 & & \\
\hline \multicolumn{4}{|l|}{$\begin{array}{l}\text { Age of mother at birth of youngest infant } \\
\text { (years) }(n=199)\end{array}$} \\
\hline$\leq 18(n=7)$ & 43 & $0.0357^{\dagger}$ & Fisher's exact \\
\hline $19-34(n=165)$ & 10 & & \\
\hline$\geq 35(n=27)$ & 15 & & \\
\hline
\end{tabular}

language delays (sample percentage of 18\%) than infants of mothers who have less than three children $\left(9 \% ; \chi^{2}, p=0.054\right)$.

- Living in informal housing or staying with others showed a significantly lower prevalence in language delays (10\%) compared with living with caregiver in their own house $\left(21 \% ; \chi^{2}, p=0.024\right)$.

- Language delays in infants born to mothers who were 18 years or younger $(43 \%)$ and mothers aged 35 years or older $(15 \%)$ were significantly higher than those born to mothers between the ages of 19 and 34 years (10\%; Fisher's exact test, $p=0.035)$.

The outcome of the log linear analysis is shown in Table 3 with the four risk factors with the strongest association with language delay presented as combined risk factors. The indices were used to calculate the probabilities of combined risk factors by multiplying the overall mean effect (value of the intercept of the log linear model) with the index of the combination of categories of risk factors under consideration.

A probability of $21 \%$ was associated with language delay in infants with two or more siblings, born to a mother aged 19 - 34 years with limited education who lives in informal housing or with others. In contrast, infants with two or more siblings born to a mother aged 19 - 34 years with a Grade $11-12$ and/or tertiary education living in informal housing or with others, only had a $10 \%$ risk to present with a language delay (Table 3).

\section{Discussion}

Few studies have reported prevalence of communication disorders under the age of 2 years. $^{[1,4]}$ The prevalence $(13.4 \%)$ of communication disorders in the sample population is higher than the prevalence rates $(5.6 \%)$ reported in previous research conducted in the UK for infants aged 0 2 years. ${ }^{[1]} \mathrm{A}$ median prevalence of $5 \%$ for speech and language delays in 2-year-olds was also reported in a systematic review conducted in $2000 .^{[4]}$

A study conducted in the UK reported that $20 \%$ of referrals (during 1999 - 2000) of children of all ages were for receptive language difficulties, $17 \%$ for expressive language difficulties and $29 \%$ for speech difficulties. ${ }^{[1]}$ Of the $20 \%$ of children with receptive language delays $6 \%$ were aged between 0 and 2 years, and of the $17 \%$ of all children with expressive language delays $13 \%$ were from the same cohort. ${ }^{[1]}$ Similar results were yielded by two other studies, one conducted in the USA, and the other a systematic review where $15 \%$ of 2 -yearolds presented with expressive language delays. ${ }^{[9,10]}$ Of the current sample population $(N=201) 11 \%$ of infants, aged 6 - 12 months, presented with delays in expressive language, 
Table 3. Associated probability of combined risk factors predisposing language delay

\begin{tabular}{|c|c|c|c|c|}
\hline Parameter & Combination of categories & Index & Odds & $p$-value $(\%)$ \\
\hline Overall mean effect & & 0.14 (intercept) & & \\
\hline \multirow[t]{8}{*}{$\begin{array}{l}\text { Age of mother, number of children, } \\
\text { education level, housing status }\end{array}$} & $\begin{array}{l}19 \text { - } 34 \text { years, }<3 \text { children, Grade } 11 / 12 \text { and/or tertiary } \\
\text { education, informal housing/staying with others }\end{array}$ & 0.42 & 0.059 & $0.056(6)$ \\
\hline & $\begin{array}{l}19-34 \text { years, }<3 \text { children, Grade } 10 \text { or less, informal housing/ } \\
\text { staying with others }\end{array}$ & 0.27 & 0.038 & $0.037(4)$ \\
\hline & 19 - 34 years, $<3$ children, all education levels, home owners & 1.46 & 0.204 & $0.169(17)$ \\
\hline & $\begin{array}{l}19 \text { - } 34 \text { years, } \geq 3 \text { children, Grade } 10 \text { or less, informal housing/ } \\
\text { staying with others }\end{array}$ & 1.89 & 0.264 & $0.209(21)$ \\
\hline & $\begin{array}{l}19 \text { - } 34 \text { years, } \geq 3 \text { children, Grade } 11 / 12 \text { and/or tertiary } \\
\text { education, informal housing/staying with others }\end{array}$ & 0.82 & 0.115 & $0.103(10)$ \\
\hline & 19 - 34 years, $\geq 3$ children, all education levels, home owners & 2.60 & 0.364 & $0.267(27)$ \\
\hline & $\begin{array}{l}\geq 35 \text { years, any number of children, all education levels, } \\
\text { informal housing/staying with others }\end{array}$ & 0.99 & 0.139 & $0.122(12)$ \\
\hline & $\begin{array}{l}\geq 35 \text { years, any number of children, all education levels, home } \\
\text { owners }\end{array}$ & 1.54 & 0.216 & $0.178(18)$ \\
\hline
\end{tabular}

which is similar to previous research findings for a slightly older cohort. ${ }^{[9,10]}$

High prevalence rates for communication and more specifically language delays, reported in the current study, may be ascribed to multiple risks present in the target population that may influence their communication development. Language delay was significantly associated with three risk factors: housing status $(p=0.0241)$, age of the mother $(p=0.035)$ and number of children in the home $(p=0.054)$. Infants with parents who are home owners were more at risk of language delays than those who stayed with others or in informal housing. The diversity of neighbourhoods in which infants live shape their social learning independent of their caregiver and/or family interaction. ${ }^{[24]}$ The diverse neighbourhood of informal settlements or living with others appears to aid language development in infants. Consequently what was deemed a risk factor in the past ${ }^{[11]}$ may facilitate more opportunities for communication interactions, and may be conducive to social language learning. Investigation into this complex interaction is however needed.

The effect of combined risk factors on language development revealed that infants in the current study were at greatest risk $(27 \%$ probability) of developing a language delay when: $(i)$ mothers were between the ages of 19 and 34 years; (ii) parents own their own home; and (iii) there are three or more children in the household.

Although high rates of spontaneous resolution of language delays have been reported in the past, ${ }^{[2,25]}$ association between language outcomes of children with delayed expressive language onset has been established. ${ }^{[5,26]}$ Making a definitive diagnosis of a socialcommunication delay is difficult at young ages. ${ }^{[27]}$ Nevertheless the most important phase of communication acquisition and development takes place between 8 and 24 months. ${ }^{[2,28]}$ As a result, early detection of developmental risks is important regardless of the final diagnosis, especially since a variety of developmental problems can lead to language delays. ${ }^{[27]}$

After the identification of risk factors, collaboration among primary healthcare workers, social services and community early intervention providers is crucial. ${ }^{[29]}$ Clinicians should regularly advise on, and make parents aware of the value of talking frequently with their children, modelling and expanding their child's utterances and actively teaching new words. ${ }^{[29]}$ However, challenged families, who are exposed to multiple risks, may not respond well to brief advice. ${ }^{[29]}$ Collaboration with community healthcare workers as part of community-orientated primary healthcare in SA may improve responsiveness of these families as continued support will be provided. ${ }^{[30]}$ Future research should evaluate the implementation of preventive measures such as awareness campaigns and developmental screening and surveillance as part of the communityorientated primary healthcare initiative.

\section{Conclusion}

In the current study $13 \%$ of infants between 6 and 12 months from an underserved primary healthcare context presented with communication delays. Specifically expressive language delays were most commonly detected in these infants. Association between three risk factors (i.e. housing status, age of mother and number of siblings) and language delays was established for this age cohort of infants. Furthermore, the probability of language delay when exposed to these risks in combination has demonstrated that infants were at greatest risk when mothers were between the ages of 19 and 34 years, when the parents own their own home and when there are three or more children in the household. Since many infants are exposed to these risks in SA the implementation of preventive measures such as awareness campaigns and developmental screening and surveillance should be prioritised.

Acknowledgements. The authors would like to acknowledge the Mellon Foundation for funding the vulnerable children programme of the Faculty of Humanities, University of Pretoria, the COPC living laboratory of the University of Pretoria, the National Research Foundation, and Department of Statistics, University of Pretoria for their assistance in the data processing and analysis. We would also like to acknowledge the Vice Chancellor's Academic Development Grant for funding the research. Mrs Ahmed and Mrs Bogatsu are also acknowledged for their contribution.

\section{References}

1. Broomfield J, Dodd B. Children with speech and language disability: Caseload characteristics. Int J Lang Commun Disord 2004;39(3):303-324. [http://dx.doi. org/10.1080/13682820310001625589]

2. Eadie PA, Ukoumunne O, Skeat J, et al. Assessing early communication behaviours: Structure and validity of the Communication and Symbolic Behaviour Scales-Developmental Profile (CSBS-DP) in 12-month-old infants. Int J Lang Commun Disord R Coll Speech Lang Ther 2010;45(5):572-585. [http://dx.doi.org/10.3109/13682820903277944]

3. Young AR, Beitchman JH, Johnson C, et al. Young adult academic outcomes in a longitudinal sample of early identified language impaired and control children. J Child Psychol Psychiatry 2002;43(5):635-645. [http://dx.doi. org/10.1111/1469-7610.00052] 
4. Law J, Boyle J, Harris F, Harkness A, Nye C. Prevalence and natural history of primary speech and language delay: Findings from a systematic review of the literature. Int J Lang Commun Disord 2000;35(2):165-188. [http://dx.doi. org/10.1080/136828200247133]

5. Hawa VV, Spanoudis G. Toddlers with delayed expressive language: An overview of the characteristics, risk factors and language outcomes. Res Dev Disabil 2014;35(2):400-407. [http://dx.doi.org/10.1016/j.ridd.2013.10.027]

6. McLeod S, McKinnon DH. Prevalence of communication disorders compared with other learning needs in 14500 primary and secondary school students. Int J Lang Commun Disord 2007;42(Suppl 1):37-59. [http://dx.doi. org/10.1080/13682820601173262]

7. Paul TJ, Desai P, Thorburn MJ. The prevalence of childhood disability and related medical diagnoses in Clarendon, Jamaica. West Indian Med J 1992;41(1):8-11.

8. Harasty J, Reed VA. The prevalence of speech and language impairment in two Sydney metropolitan schools. Aust J Hum Commun Disord 1994;22(1):1-23. [http://dx.doi.org/10.3109/asl2.1994.22.issue-1.01]

9. Samuels A, Slemming W, Balton S. Early childhood intervention in South Africa in relation to the developmental systems model: Infants Young Child 2012;25(4):334-345. [http://dx.doi.org/10.1097/IYC.0b013e3182673e12]

10. Evans GW. Child development and the physical environment. Annu Rev Psychol 2006;57(1):423-451. [http://dx.doi.org/10.1146/annurev. psych.57.102904.190057]

11. Van der Linde J, Kritzinger A, Redelinghuys A. The identification process in early communication intervention (ECI) by primary health care personnel in Ditsobotla sub-district. S Afr J Commun Disord 2009;56:48-59.

12. Kathard H, Pillay M. Promoting change through political consciousness: A South African speech-language pathology response to the World Report on Disability. Int J Speech Lang Pathol 2013;15(1):84-89. [http://dx.doi.org/10.3 109/17549507.2012.757803]

13. Greenwood CR, Buzhardt J, Walker D, McCune L, Howard W. Advancing the construct validity of the Early Communication Indicator (ECI) for infants and toddlers: Equivalence of growth trajectories across two early head start samples. Early Child Res Q 2013;28(4):743-758. [http://dx.doi.org/10.1016/j. ecresq.2013.07.002]

14. Statistics South Africa. Census 2011. https://www.statssa.gov.za/Census2011/ default.asp (accessed 20 February 2014)

15. Statistics South Africa. Poverty Trends in South Africa: An examination of absolute poverty between 2006 and 2011. Report No.: 03-10-06. http://beta2. statssa.gov.za/publications/Report-03-10-06/Report-03-10-06March2014.pdf (accessed 5 May 2014).

16. Mayosi BM, Benatar SR. Health and health care in South Africa - 20 years after Mandela. N Engl J Med 2014;371(14):1344-1353. [http://dx.doi.org/10.1056/ NEJMsr1405012]

17. Rossetti L. The Rossetti Infant-Toddler Language Scale: A Measure of Communication and Interaction: Examiner's Manual. Austin: Linguisystems, 2006.
18. Desmarais C, Sylvestre A, Meyer F, Bairati I, Rouleau N. Three profiles of language abilities in toddlers with an expressive vocabulary delay: Variations on a theme. J Speech Lang Hear Res 2010;53(3):699. [http://dx.doi. org/10.1044/1092-4388(2009/07-0245)]

19. Sylvestre A, Mérette C. Language delay in severely neglected children: A cumulative or specific effect of risk factors? Child Abuse Negl 2010;34(6):414428. [http://dx.doi.org/10.1016/j.chiabu.2009.10.003]

20. Dettman SJ, Pinder D, Briggs RJS, Dowell RC, Leigh JR. Communication development in children who receive the cochlear implant younger than 12 months: Risks versus benefits. Ear Hear 2007;28(Suppl):11S-18S. [http://dx.doi. org/10.1097/AUD.0b013e31803153f8]

21. Steiner AM, Goldsmith TR, Snow AV, Chawarska K. Practitioner's guide to assessment of autism spectrum disorders in infants and toddlers. J Autism Dev Disord 2012;42(6):1183-1196. [http://dx.doi.org/10.1007/s10803-011-1376-9]

22. Desmarais C, Sylvestre A, Meyer F, Bairati I, Rouleau N. Systematic review of the literature on characteristics of late-talking toddlers. Int J Lang Commun Disord R Coll Speech Lang Ther 2008;43(4):361-389. [http://dx.doi. org/10.1080/13682820701546854]

23. Horwitz SM, Irwin JR, Briggs-Gowan MJ, Bosson Heenan JM, Mendoza J, Carter AS. Language delay in a community cohort of young children. J Am Acad Child Adolesc Psychiatry 2003;42(8):932-940. [http://dx.doi.org/10.1097/01. CHI.0000046889.27264.5E]

24. Howard LH, Carrazza C, Woodward AL. Neighborhood linguistic diversity predicts infants' social learning. Cognition 2014;133(2):474-479. [http://dx.doi. org/10.1016/j.cognition.2014.08.002]

25. Reilly S, Wake M, Bavin EL, et al. Predicting language at 2 years of age: A prospective community study. Pediatrics 2007;120(6):e1441-e1449. [http:// dx.doi.org/10.1542/peds.2007-0045]

26. Rice ML, Taylor CL, Zubrick SR. Language outcomes of 7-year-old children with or without a history of late language emergence at 24 months. J Speech Lang Hear Res 2008;51(2):394-407. [http://dx.doi.org/10.1044/10924388(2008/029)]

27. Ben-Sasson A, Habib S, Tirosh E. Feasibility and validity of early screening for identifying infants with poor social-communication development in a well-baby clinic system. J Pediatr Nurs 2014;29(3):238-247. [http://dx.doi. org/10.1016/j.pedn.2013.11.001]

28. Reilly S, Eadie P, Bavin EL, et al. Growth of infant communication between 8 and 12 months: A population study. J Paediatr Child Health 2006;42(12):764770. [http://dx.doi.org/10.1111/j.1440-1754.2006.00974.x]

29. Glascoe FP, Leew S. Parenting behaviors, perceptions, and psychosocial risk: Impacts on young children's development. Pediatrics 2010;125:313-319. [http:// dx.doi.org/10.1542/peds.2008-3129]

30. Bam N, Marcus T, Hugo J, Kinkel H-F. Conceptualizing Community Oriented Primary Care (COPC) - the Tshwane, South Africa, health post model. Afr J Prim Health Care Fam Med 2013;5(1):1-3. [http://dx.doi.org/10.4102/phcfm. v5i1.423] 